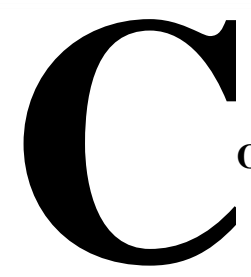

\title{
OMPETITIVE OR COOPERATIVE PRODUCTIVE CLUSTER? CASE OF THE FURNITURE CLUSTER OF CARMO OF CAJURU (MG)
}

\author{
${ }^{1}$ Moisés Habib Bechelane Maia \\ ${ }^{2}$ Luiz Guilherme Rodrigues Antunes \\ ${ }^{3}$ Cléber Carvalho de Castro
}

\begin{abstract}
\end{abstract}
Objective: The aim of this article is to characterize the cooperation process in the furniture cluster of Carmo do Cajuru (MG).

Methodology: We divided the study into two stages. The first stage was quantitative and for this we applied a survey. The second stage was qualitative, with semi-structured interviews conducted. Thus, the use of two techniques of data collection was sought to deepen results, as well as to triangulate data.

Originality/Relevance: The analysis of relations of competitiveness and cooperation in clusters makes it possible to understand the dynamics of such agglomerates, especially in emerging countries such as Brazil.

Main Results: We found that, although the participant subjects have different perceptions about competition and cooperation, they agree that competition stands out in relation to cooperation. In addition, we obtained two groups of companies by multivariate analysis, in which the first one was composed of micro and small companies, while the second group was composed of larger companies. Finally, we found that the cluster is characterized as informal, and as such, it pass the responsibilities of its interactions to an intermediary body, The cluster also presents vestiges of cooperation and its competitiveness is more destructive.

Theoretical contributions: The theoretical contribution is the consolidation of the network discipline, as well as of the national literature on the subject.

Keywords: Clusters. Cooperation. Competition.

\section{Cite it like this:}

Maia, M., Antunes, L., \& Castro, C. (2019). Aglomerado Produtivo Competitivo ou Cooperativo? O Caso do Aglomerado Moveleiro do Carmo do Cajuru (MG). Revista Ibero-Americana De Estratégia, 18(1). 106-125. https://doi.org/10.5585/ijsm.v18i1.2707

\footnotetext{
${ }^{1}$ Universidade Federal de Lavras (UFLA), Minas Gerais, Brasil. Email: moiseshabib@yahoo.com.br Orcid Id: https://orcid.org/0000-0002-2887-2885 ${ }^{2}$ Universidade Federal de Lavras (UFLA), Minas Gerais, Brasil. Email: luguiantunes@yahoo.com.br
https://orcid.org/0000-0003-2997-2949

${ }^{3}$ Universidade Federal de Lavras (UFLA), Minas Gerais, Brasil. Email: clebercastrouai @ gmail.com Orcid Id: https://orcid.org/0000-0002-4122-2748
} 
Aglomerado produtivo competitivo ou cooperativo? $\mathrm{O}$ caso do aglomerado moveleiro do carmo do cajuru (MG)

\section{AGLOMERADO PRODUTIVO COMPETITIVO OU COOPERATIVO? O CASO DO AGLOMERADO MOVELEIRO DO CARMO DO CAJURU (MG)}

\section{Resumo}

Objetivo: o objetivo do presente artigo é caracterizar o processo de cooperação no aglomerado moveleiro do Carmo do Cajuru (MG).

Metodologia: a pesquisa foi dividida em duas etapas, na qual a primeira etapa (quantitativa) aplicou-se uma survey, e para a etapa posterior (qualitativa) desenvolveu-se entrevistas semiestruturadas. Assim, a utilização de duas técnicas de coleta de dados buscou-se aprofundar resultados, assim como triangular os dados.

Originalidade/Relevância: a análise de relações de competitividade e cooperação em aglomerados permite compreender as dinâmicas de atuação de tais aglomerados, sobretudo em países emergentes como o Brasil.

Resultados: constatou-se que, embora os sujeitos possuam percepções diferentes sobre competição e cooperação, ambos concordam que a competição se sobressai em relação a cooperação. Além disso, pela análise multivariada, foram obtidos dois grupos de empresas, sendo que o primeiro foi composto de micro e pequenas empresas, enquanto o segundo grupo foi composto por empresas maiores. Por último, verificou-se que o aglomerado é caracterizado como informal, e como tal, atribui as responsabilidades de suas interações a um órgão intermediador, apresenta vestígios de cooperação e a competitividade é mais destrutiva.

Contribuições Teóricas: como contribuições do estudo destaca-se a consolidação teórica da disciplina de rede, bem como da literatura nacional sobre a temática.

Palavras-Chave: Aglomerados. Cooperação. Competição.

\section{¿AGLOMERADO PRODUCTIVO COMPETITIVO O COOPERATIVO? EL CASO DEL AGLOMERADO MOVELEIRO DEL CARMELO DEL CAJURU (MG)}

\section{Resumen}

Objetivo: el objetivo del presente artículo es caracterizar el proceso de cooperación en el aglomerado mueblero de Carmo do Cajuru (MG).

Metogología: la investigación está dividida en dos etapas. En la primera etapa (cuantitativa) se aplicó el método survey, y para la etapa posterior (cualitativa) se desarrollaron entrevistas semiestructuradas. De ese modo, la utilización de dos técnicas de recolección de datos buscó profundizar resultados, así como triangularlos.

Originalidad/pertinencia: El análisis de relaciones de competitividad y de cooperación en aglomerados, permite comprender las dinámicas de actuación de tales aglomerados, principalmente en países emergentes como Brasil.

Principales Resultados: Como principales resultados, se constató que, aunque los sujetos poseen percepciones diferentes sobre competición y cooperación, ambos están de acuerdo que la competición se destaca en relación a la cooperación. Además, por el análisis multivariado se obtuvo dos grupos de empresas. El primer grupo está compuesto de micro y pequeñas empresas, mientras que el segundo se compone de empresas más grandes. Por último, se verificó que el aglomerado se caracteriza como informal y, como tal, 
atribuyelas responsabilidades de sus interacciones a una organización intermedio, presenta vestigios de cooperación y la competitividad es más destructiva.

Teórica Contribuciones: Como contribuciones del estudio se destaca la consolidación teórica de la disciplina de red, así como de la literatura nacional sobre la temática.

Palabras Clave: Aglomerados. Cooperación. Competición

\section{INTRODUÇÃO}

Durante as últimas décadas, o ambiente econômico e organizacional passou por uma série de modificações que exigiram das organizações capacidades de flexibilização e de responder rapidamente as mudanças ambientais. Nesse sentido, duas eras puderam ser destacadas por Snow (2015), no qual alteraram profundamente as formas como as organizações se relacionavam umas com as outras e, principalmente, desenvolviam negócios.

A primeira era, denominada de competição (1800 a 1970), foi marcada pela criação de valor econômico no mercado, por meio da proteção do know-how e da defesa da posição da empresa no mercado. Nesse momento incentivou-se comportamentos competitivos entre empresas e indivíduos, ao longo do tempo, sobre como e onde competir, bem como onde e como cooperar (Snow, 2015).

A ação dos indivíduos, portanto, eram embasadas no próprio interesse e na maximização dos retornos que poderiam esperar de seus esforços. Além disso, a grande corporação tomou lugar da micro e pequena empresa (MPE) em todos os setores, no qual a ampliação da escala e a coordenação administrativa possibilitou redução de custos, maior produtividade e a consequente elevação dos lucros (Balestrin \& Verschoore, 2016).

A era seguinte (iniciada ao final de 1970) foi o resultado de série de modificações ambientais da era anterior, em que resultou no declínio das grandes empresas. Assim, os negócios necessitavam estabelecer novas relações econômicas e comerciais, consolidando o que veio a ser conhecido como a nova competição (Balestrin \& Verschoore, 2016; Nohria, 1992; Best, 1990), ou a era da cooperação (Snow, 2015). A base dessa era, portanto, recai na cooperação, que ocorre quando uma pessoa, ou grupo, ajuda o outro na realização de alguma atividade que trará benefícios aos envolvidos (Snow, 2015; Evans, 2003). Por conseguinte, emerge os empreendimentos cooperativos, em que as partes optam por trabalhar conjuntamente para atingir seus objetivos mútuos, o que não exclui o interesse próprio e a interdependência (Snow, 2015).

Nesse momento também emerge um novo paradigma: as redes de empresas (Nohria, 1992; Snow, 2015), que podem ser consideradas como sistemas de nós interligados, numa estrutura formal, dinâmica e com atributos específicos, que por meio de ações padronizadas e descentralizadas dos atores, permitem a adequação das empresas no ambiente competitivo (Castells \& Cardoso, 2006; JohnsonCramer, Parise \& Cross, 2007).

Assim, ao se aliar o fator da competição com as teorias das redes interorganizações, emerge-se os aglomerados produtivos, que segundo Porter (1999), são agrupamentos de empresas em uma região de um determinado setor de atividade. Dentro deste contexto, os aglomerados afetam a capacidade de competição das empresas pelo incremento de produtividade, maior acesso a informações especializadas, expertise técnico e científico e direcionamento das inovações (Porter, 1999). Além disso, os aglomerados consolidam as práticas cooperativas entre os agentes, propagando processos conjuntos de aprendizado e capacitação (Britto, 2004). Em especial, a cooperação faz com que o aglomerado ganhe força e eficiência, além de intensificar o ritmo de introdução de inovações. Sob esta ótica, o aglomerado aliado à visão de cooperação reforça o potencial e o desempenho competitivo dos atores inseridos na mesma (Balestro, 2004).

No entanto, quais processos de cooperação podem estar presentes em um aglomerado produtivo? Para responder a esse questionamento, recorreu-se ao aglomerado do setor moveleiro do município de Carmo do Cajuru (MG). Assim sendo, o objetivo principal dessa pesquisa é caracterizar o processo de cooperação no aglomerado moveleiro do Carmo do Cajuru (MG). Como objetivos específicos buscou-se identificar a rede de empresas e estrutura de apoio ao desenvolvimento do aglomerado no município e 
Aglomerado produtivo competitivo ou cooperativo? $\mathrm{O}$ caso do aglomerado moveleiro do carmo do cajuru (MG)

caracterizar os processos de cooperação e competição do cluster.

Como justificativa teórica para o presente estudo, advoga-se que a competitividade e a instabilidade do mercado no ambiente econômico globalizado vêm se tornando um grande desafio para a gestão empresarial (Balestrin \& Verschoore, 2016; Snow, 2015; Nohria, 1992). Diante desse cenário, o estudo de micro e pequenas empresas inseridas em um aglomerado ajuda a entender as sinergias da concentração especial de atividades produtivas. Portanto, à medida que a competição aumenta, a cooperação entre as empresas se torna fator chave para que as empresas possam alcançar resultados mais expressivos (Snow, 2015).

Já para a justificativa social aponta-se a relevância do aglomerado para o município, visto que, conforme evidenciado por alguns autores (Linhares, 2008; Mendonça, 2008; Matheus, 2003), o município vem se destacando na produção de móveis em madeira por micro e pequenas empresas aglomeradas, voltadas para o atendimento das classes A e B. Além disso, o setor é de extrema importância para o aspecto socioeconômico do município, uma vez que absorve grande parte da mão de obra existente na cidade. Além dessa introdução, o artigo está estruturado em mais quatro seções. A seção seguinte apresenta uma breve revisão de literatura acerca dos aglomerados, bem como da competição e cooperação aplicados a esse formato.

A terceira seção apresenta os métodos e procedimentos utilizados neste estudo. Na quarta seção apresenta-se os resultados e as discussões provenientes dos dados coletados. E, por fim, a última seção apresenta as considerações finais.

\section{AGLOMERAÇÕES PRODUTIVAS, COMPETIÇÃ̃O E COOPERAÇÃOO}

A literatura que trata das aglomerações locais parte do legado de Marshall (1966), que identificou que a maior expressão do fenômeno das externalidades e retornos crescentes poderia ser encontrada em complexos geográficos de atividades econômicas (Fan \& Scott, 2003). Desse modo, as concentrações geográficas de atividades econômicas apresentam características que permitem ou facilitam a geração e aproveitamento de vantagens para o desenvolvimento conjunto de empresas. Assim, o aglomerado se configura como uma localidade geográfica, no qual a proximidade física de empresas e instituições salvaguarda afinidades e aumenta a frequência e impactos das interações entre os agentes - clientes, fornecedores, associações, governos e outros (Pedrosa, Antunes, Morais \& Rodrigues, 2018; Porter, 1999). Desse modo, um dos pontos cruciais para a formação de um aglomerado é a proximidade geográfica. Segundo Porter (1998) e Vale (2007) o termo aglomeração - produtiva, científica, tecnológica e/ou inovativa - tem como aspecto central a proximidade territorial de agentes econômicos, políticos e sociais.

Segundo a visão marshalliana, pode-se identificar três motivos vantajosos para o agrupamento das empresas, que são: (i) a concentração geográfica, entendida como espaço social e econômico, pode atrair fornecedores especializados e locais; (ii) especialização da indústria o que acarretaria na especialização da mão de obra; e (iii) difusão da informação (Roxo, Santarossa \& Bertotti, 2011). Segundo Roxo, Santarossa \& Bertotti (2011) as teorias da localização vieram se desenvolvendo e aspectos dos retornos crescentes de escala e economia de aglomerações passaram a abarcar as discussões sobre a distribuição econômico-espaciais.

Contudo, a literatura aponta que as empresas próximas possuem condições para estreitar os vínculos com clientes, fornecedores e instituições pública e privada, o que pode proporcionar maior produtividade, gerando assim externalidades positivas, bem como externalidades negativas, quando indesejadas (Puga \& Fernandes, 2014).

Diante disso, Cunha (2002) e Marshall (1966) ressalta que a concentração geográfica e setorial de empresas, ao gerar externalidades produtivas e tecnológicas, favorece a eficiência coletiva como redução dos custos de transação, diferenciação produtiva, economias de escala e etc.

Ainda nesse sentido, Johansson (2005) corrobora apontando que as externalidades podem ser apresentar-se de duas formas: pecuniárias e tecnológicas. Desse modo, as externalidade pecuniárias ocorrem por transações de mercado, ou seja, por vínculos interorganizacionais, como redução de cursos de transação, compras de matériasprimas, vendas e distribuição. Já as externalidades tecnológicas podem ser obtidas fora do mercado, pois estão relacionadas com os custos de produção.

Exemplifica-se, portanto os fluxos de conhecimentos e decorrentes em termos de desenvolvimento de produtos, verificação de 
tendências de mercado e tecnologias (Puga \& Fernandes, 2014).

Além das externalidades positivas, outros benefícios encontrados nesse tipo de arranjo são: proximidade com fornecedores, acesso a mão de obra especializada, indústrias correlatas e de apoio, acesso a informações e compartilhamento de conhecimentos, marketing coletivo, inovação e aprendizado interativo, facilidade de formação de novas empresas, cooperação e interação entre as empresas.

Em extensa literatura, os aglomerados podem ser reconhecidos como cluster, arranjos produtivos locais, sistemas locais de produção, distritos industriais e outras formas. Para Lemos (1997) alguns aspectos comuns podem ser estabelecidos dentre essa diversidade de denominações, sobretudo ao que se refere a atores e características.

Dessa forma, ao que se trata de atores, os aglomerados podem ser constituir tanto de grupos de pequenas empresas quanto por pequenas empresas nucleadas por grandes, ou de associações de empresas, instituições de suporte, serviços, ensino e pesquisa, fomento, etc. Já em relação as suas características, os arranjos podem ter intensa divisão de trabalhos entre as firmas; flexibilidade de produção e organização; especialização; mão de obra qualificada; competição entre firmas baseada em inovação; estreita colaboração entre firmas e demais agentes; fluxo intenso de informações; identidade cultural entre os agentes; relações de confiança entre os agentes; e complementaridades e sinergias.

Entretanto, deve-se ressaltar que, assim como Lübeck, Wittmann e Silva (2012) apontam, as diferentes nomenclaturas descrevem diferentes momentos de desenvolvimento dos aglomerados, visto que as simples aglomerações de empresas de uma mesma cadeia produtiva não necessariamente pode ser caracterizar como um arranjo produtivo local ou até mesmo um sistema local de produção e inovação. Numa tentativa de propor uma diferenciação dos aglomerados, Iacomo e Negano (2007) apresentam três classificações, Figura 1, em que tais arranjos podem se configurar.

\begin{tabular}{|c|c|}
\hline Tipos de Aglomerados & Características \\
\hline Informal & $\begin{array}{l}\text { - Constituído por micro e pequenas empresas; } \\
\text { - Baixa sofisticação tecnológica e capacidade gerencial; } \\
\text { - Mão de obra de baixa qualificação, infraestrutura inadequada, ausência de } \\
\text { apoio financeiro e poucas inovações; } \\
\text { - Em relação à coordenação e à cooperação, nesse tipo de aglomerado as } \\
\text { relações são fracas, com pouca confiança, muita competição e baixo } \\
\text { compartilhamento de informação; } \\
\text { - Prevalecentes em países em desenvolvimento como o Brasil, e o papel do } \\
\text { Estado, através de políticas públicas que visem o fornecimento de serviços } \\
\text { tecnológicos, treinamento e crédito, tem mostrado ser de fundamental } \\
\text { importância para o crescimento desses aglomerados. }\end{array}$ \\
\hline Organizado & $\begin{array}{l}\text { - Constitui-se por empresas de pequeno e médio porte; } \\
\text { - Maiores níveis de competência; } \\
\text { - Caracteriza-se pela cooperação e pelo trabalho em rede entre empresas } \\
\text { participantes; } \\
\text { - Apresentam flexibilidade e resposta rápida ao mercado, por possuírem } \\
\text { capacidade para adaptar tecnologias e desenvolver novos produtos e processos; } \\
\text { - Proporciona maior competitividade, refletindo em níveis de exportação mais } \\
\text { elevados; } \\
\text { - Esses aglomerados não são organizados suficientemente para apoiar um } \\
\text { processo de melhoria contínua, o que limita a geração de inovações significativas; } \\
\text { - A competição, como nos informais, também é elevada; } \\
\text { - A cooperação, embora se apresente com maior intensidade, ainda não é } \\
\text { sustentada. }\end{array}$ \\
\hline Inovador & $\begin{array}{l}\text { - Formado por grandes, pequenas e médias empresas; } \\
\text { - Alta capacidade de criação e um processo contínuo de inovação ao longo do } \\
\text { tempo; } \\
\text { - A confiança, cooperação e capacidade de inovação se apresentam em grau } \\
\text { elevado; } \\
\text { - A mão de obra é qualificada e a infraestrutura é adequada; }\end{array}$ \\
\hline
\end{tabular}


Aglomerado produtivo competitivo ou cooperativo? $\mathrm{O}$ caso do aglomerado moveleiro do carmo do cajuru (MG)

- Os aglomerados inovadores têm forte presença no mercado internacional, com elevados índices de exportação;

- A presença do Estado e do governo local têm sido de grande importância para o desenvolvimento e coordenação desses aglomerados;

- Os países desenvolvidos, em geral, apresentam experiências com aglomerados inovadores.

Figura 1. Classificação dos aglomerados.

Nota Fonte: Iacono, A., \& Nagano, M. S. (2007). Uma análise e reflexão sobre os principais instrumentos para o desenvolvimento sustentável dos arranjos produtivos locais no Brasil. Revista Gestão Industrial, 3(1).

Contudo, o que se deve enfatizar é que as aglomerações se configuram como concentrações espaciais de agentes econômicos, políticos e sociais (Erber, 2008), que podem proporcionar vantagens as empresas, especialmente as MPEs.

A relevância dos APLs centra-se, portanto, em permitir que, por meio do compartilhamento de certas atividades, as empresas de menor porte agreguem vantagens de grandes empresas por meio de funções como logística, marca ou tecnologia, alcançando maiores chances para competir no mercado (Cassaroto Filho \& Pires, 2001). As aglomerações colaboram ainda para a redução dos custos de transação, tanto nos processos de negociação quanto nos de monitoramento dos contratos, figurando como uma forma de estrutura híbrida para as empresas participantes (Williamson, 2003; Enright, 2003).

Outros custos incorridos nas organizações podem ser reduzidos por meio da constituição de APLs: custos de produção reduzidos por meio de ganhos de escala e inovação com processos conjuntos de P\&D; custos de aprendizado reduzidos pelo fácil acesso a um grande número de agentes e informações mais baratas, custos de oportunidade reduzidos por um uso mais eficiente dos recursos disponíveis e tomadas de decisões mais precisas e dinâmicas. Além destes, o custo do bem-estar social pode aumentar ou diminuir de acordo com as posturas adotadas pelos participantes da rede em relação aos melhoramentos das condições de trabalho, dos possíveis incentivos ao aumento da concorrência, entre outros (Ring, 1999).

Entretanto ressalta-se que os aglomerados são vistos como questão estratégica (Pedrosa et al., 2018; Thomazi, 2006), pois disponibilizam apresentam diversos benefícios para as empresas nela inseridas. Tais benefícios podem ser obtidos, sobretudo, por dois aspectos intrínsecos dos aglomerados: a competitividade e a cooperação.
Ao se que refere a competitividade, a participação em aglomerações pode aumentar a capacitação das empresas, especialmente nos fatores competitivos empresariais que envolvem a gestão da empresa, o desenvolvimento dos recursos $\mathrm{e}$ as escolhas estratégicas (Ferraz, Kupfer \& Haguenauer, 1995; Rangone, 1999).

Machado (2003) menciona que as vantagens competitivas que motivam determinada empresa a se localizar próxima geograficamente a outras empresas podem ser genericamente classificadas em economias externas e internas. Assim, as economias internas estão relacionadas com a proximidade física e cognitiva que podem criar condições para relações cooperativas horizontais entre as empresas (Crocco, Galinari, Santos, Lemos \& Simões, 2006); e as economias externas têm origem em condições físicas favoráveis, como a proximidade de matérias-primas e infraestrutura de transportes (Machado, 2003).

Ao que se trata da cooperação, Saublens (1999) frisa que em muitos países, pequenas e médias empresas estão se aglomerando em locais e regiões e passando a desenvolver uma diversidade de relações sociais baseadas na complementaridade, interdependência e na cooperação. A cooperação entre pequenas empresas, portanto, aparece como uma maneira destas assegurarem sua sobrevivência, além de garantir um desenvolvimento equilibrado para a sociedade (Casarotto Filho \& Pires, 2001).

Assim, os aglomerados produtivos permitem que as empresas de pequeno porte aumentem suas oportunidades de cooperarem com outras empresas e instituições diversas, dando a elas maior potencial de competitividade no mercado global por meio de melhores condições de desenvolvimento de suas atividades (Galbraith, Rodrigues \& DeNoble, 2008; Gomez \& Helsing, 2008). Nesse sentido Oliveira e Gonçalves (2011) apontam que as relações de cooperação permitem que as empresas desenvolvam a vantagem competitiva, por desfrutar de benefícios como acesso facilitado à matéria-prima, mão de obra especializada, economia de escala, desenvolvimento 
de barreiras aos novos entrantes, redução de custos de transação e de pesquisas, desenvolvimento local e dentre outros fatores.

Apesar de toda expectativa em relação à cooperação, segundo o Instituto de Estudos para o desenvolvimento industrial - IEDI (2003), no Brasil, alguns estudos sobre clusters constataram que na maioria dos casos não há formas relevantes de cooperação entre as empresas, e que ela se limita à troca ou empréstimo de matérias-primas e, eventualmente, de equipamentos.

Mas há experiências positivas, onde a existência de um agente coordenador, ou a adoção de estratégias conjuntas pelas principais empresas, permitiu reduções de custos relevantes. Ademais, embora a cooperação é algo a ser visado por grupos de empresas, não é verificado boa vontade dos participantes de um aglomerado em ceder informações e técnicas a seus 'concorrentes locais'.

Dessa maneira é necessário que haja apoio por parte de outros agentes, como governo e agentes locais.

Por fim, é importante ressaltar que embora as empresas busquem ser mais competitivas, esta não exclui a possibilidade de haver a cooperação entre as mesmas. Desse modo, os aglomerados representam, nitidamente, uma combinação de competição e colaboração. A presença de muitos rivais e de fortes incentivos geralmente acirra a intensidade da competição nos aglomerados, embora a cooperação se desenvolva, boa parte dela é vertical, envolvendo setores correlatos e ocorre entre instituições locais (Porter, 1999, p. 236).

No entanto, é o padrão de competição (Ferraz, Kupfer \& Haguenauer, 1995; Possas, 1999) estabelecido nos mercados de atuação das empresas do aglomerado que influencia no tipo de cooperação em que as mesmas estão dispostas a se envolver. $\mathrm{O}$ tópico a seguir apresenta o percurso metodológico estabelecido pela pesquisa.

\section{MÉTODOS DE PESQUISA}

O presente artigo caracteriza-se como descritivo, pois pretende detalhar os fatos e fenômenos de uma realidade o mais fiel possível, de forma que se possa alcançar, com rigorosidade, as características de um indivíduo, situação ou grupo, assim como revelar as relações entre os eventos (Sellitiz, 1965; Gil, 2010).
Quanto a sua natureza, utilizou-se de métodos mistos (combinam abordagens quantitativas e qualitativas), que segundo Creswell e Clark (2017) possibilita melhor compreensão dos problemas de pesquisa do que as abordagens isoladas. Segundo Malhotra (2011, p. 122) a pesquisa quantitativa "busca uma evidência conclusiva baseada em grandes amostras representativas e, normalmente envolve alguma análise estatística". Já as pesquisas qualitativas o pesquisador está interessado em compreender quais os significados que os participantes atribuem ao fenômeno ou situação que está estudando (Godoy, 2005).

Como método de pesquisa abordado utilizou-se o estudo de caso, que segundo Yin (2005) é um estudo empírico que investiga um fenômeno atual dentro do seu contexto de realidade, quando as fronteiras entre o fenômeno e o contexto não são muito bem definidas, e são utilizadas várias fontes de evidências. Assim, a pesquisa foi realizada no aglomerado produtivo moveleiro do Carmo do Cajuru (MG). Esse aglomerado produtivo surgiu de maneira natural e sua história está relacionada com a história da empresa Mobiliadora Líder, fundada em 1945 (Diomar, 2000). O aglomerado tem se destacado no cenário nacional em virtude da produção de móveis em madeira, por micro e pequenas empresas aglomeradas, voltadas para o atendimento das classes A e B (móveis de linha alta).

Ao que se refere a coleta de dados, foi utilizado fontes primárias de dados, que são obtidos a partir da ação do pesquisador. Assim, a pesquisa em questão se dividiu em duas fases. A primeira fase, de cunho quantitativo, foi realizada mediante a coleta de dados pelo método survey durante o ano de 2011. Um levantamento tipo survey é uma pesquisa de abordagem quantitativa na qual a coleta de dados sobre uma amostra deverá fornecer dados representativos da população de interesse (Forza, 2002; Malhotra \& Grover, 1998).

Na elaboração do questionário utilizou-se escala tipo Likert de cinco pontos de concordância, em que os respondentes deveriam pontuar de (1) discordo totalmente a (5) concordo totalmente. O objetivo da aplicação desse método foi analisar as perspectivas dos empresários e das lideranças do município, bem como a visão de grande parte das empresas acerca da competição e cooperação existentes no aglomerado ao qual estão inseridos. Assim, o levantamento da população se deu segundo o Relatório Anual de Informações Sociais - RAIS (2009). 
Aglomerado produtivo competitivo ou cooperativo? $\mathrm{O}$ caso do aglomerado moveleiro do carmo do cajuru (MG)

Conforme o RAIS (2009), o município do Carmo do Cajuru, em 2009, apresentava 70 empresas ativas e registradas dentro da Classe CNAE 20/31.012 Fabricação de móveis com predominância de madeira, sendo 60 formais e 10 informais. Segundo a classificação de empresas com base no número de empregados adotado pelo SEBRAE, há 48 microempresas em Carmo do Cajuru, abrangendo 10 informais e 38 formais, produzindo $28 \%$ do total de móveis; 21 empresas são de pequeno porte, o qual são responsáveis pela produção de $32 \%$ dos móveis; e somente uma de grande porte, que fabrica $40 \%$ dos móveis da cidade, pertencente ao grupo Líder, sendo ela dividida em três unidades: mobiliadora, estofados e interiores (Mendonça, 2010).

O mix dos principais produtos das empresas é focado na fabricação de dormitórios (cama, guardaroupa, cômoda, criado); móveis de sala (estofados, racks e estantes); móveis de sala de jantar (mesa, cadeira e armário); e móveis de escritório. As vendas das empresas do aglomerado predominam para Minas Gerais, São Paulo e Rio de Janeiro, conforme Figura 2.

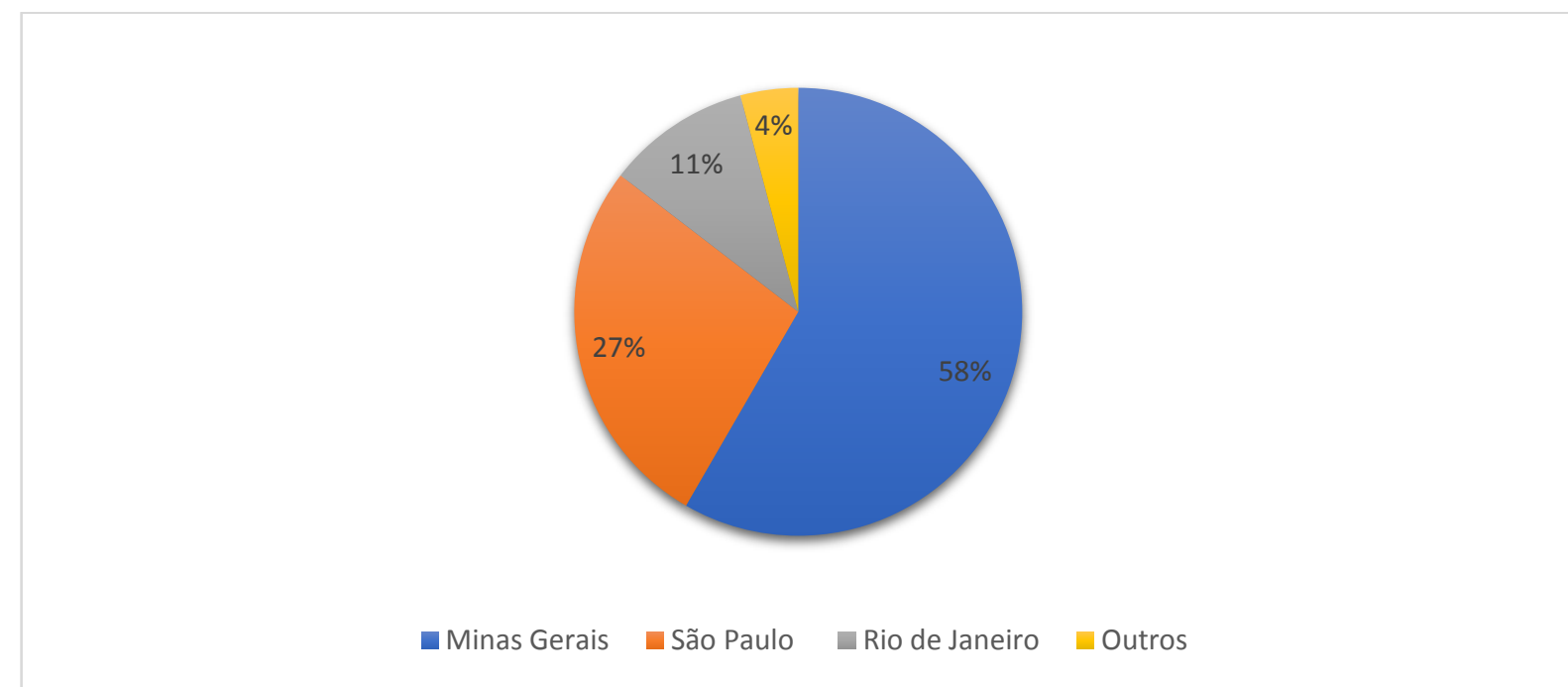

Figura 2. Destinação das vendas das empresas do aglomerado.

Nota Fonte: Mendonça, F. M. de. (2010). Formação, desenvolvimento e estruturação de arranjos produtivos locais da indústria tradicional do Estado de Minas Gerais. São Paulo: Blucher.

Desse modo, as empresas foram definidas como população alvo da pesquisa. Assim, foram enviados os questionários as organizações e obteve-se taxa de retorno de 64,28\% (45 questionários respondidos). Para Marconi e Lakatos (2005) a taxa média de devoluções dos questionários é de apenas $25 \%$ do total enviado.

$\mathrm{Na}$ segunda fase da pesquisa, de cunho qualitativo, entrevistou-se duas empresas do aglomerado, sendo cada uma delas pertencentes a cada um dos grupos obtidos pela análise de cluster (etapa quantitativa). Assim, procedeu-se entrevista semiestruturada, em que o roteiro elaborado buscou aprofundar algumas questões visualizadas durante a aplicação quantitativa da pesquisa, isto é, as questões levantadas durante as entrevistas estiveram diretamente relacionadas aos resultados obtidos na parte quantitativa.
Como plano de análise de dados, utilizou-se os softwares Statistical Package for the Social Sciences (SPSS) para análise quantitativa dos dados, no qual, desenvolveu-se análise univariada, por meio de frequência, e análise multivariada, como análise de cluster e de discriminante. A análise de cluster foi desenvolvida com o Modelo Hierárquico Ward com base em Malhotra (2011) e Maroco (2010). A hipótese estabelecida é que não haveria diferenças significativas entre o perfil e visão das empresas participantes do aglomerado.

A análise discriminante foi aplicada aos cluster extraídos na análise anterior, utilizando-se o Método Stepwise (por etapas), pois o método estima as funções discriminantes, em que as variáveis independentes entram sequencialmente conforme o poder discriminatório que elas acrescentam a 
precisão de pertinência no grupo (Hair Junior, Black, Babin, Anderson, \& Tatham, 2009). É importante ressaltar que, para essas análises, as escalas ordinais foram assumidas como intervalares para que as técnicas multivariadas pudessem ser aplicadas.

Já na análise qualitativa, utilizou-se da análise de conteúdo. A análise de conteúdo, portanto, é um conjunto de técnicas de análise das comunicações que procura obter, por procedimentos sistemáticos e objetivos, a descrição dos conteúdos das mensagens, permitindo a inferência de conhecimentos relativos às condições de produção/recepção dessas mensagens (Bardin, 2016). Para a operacionalização dessa análise, procedeu-se em três etapas: préanálise, exploração do material e tratamento dos resultados obtidos e interpretação.

Assim, na primeira etapa realizou-se a preparação e organização do material, leitura e codificação. Posteriormente, na etapa de exploração e tratamento foram localizados os trechos das narrativas mais pertinentes e adequadas as grades fechadas. Tais grades formaram-se pelas dimensões de cooperação e competição. Por último, foram analisados os trechos sob a interface da teoria de aglomerados produtivos.

Por fim, vale destacar que a utilização de duas técnicas de coleta e análise de dados proporciona a triangulação metodológica sequencial no estudo da mesma unidade empírica (Godoy, 2005; Morse, 1991; Vergara, 2015) de modo a aumentar a credibilidade da investigação, segundo os preceitos de Lincoln e Guba (1986). No próximo tópico são apresentados os dados coletados e, por conseguinte, as discussões.

\section{ANÁLISE DE DADOS}

Inicialmente, na analise univariada, questionouse os empresários sobre a presença e/ou ausência de um ambiente propício a cooperação e a competição. Como resultado, foi possível verificar que os mesmos apontaram que há pouca cooperação entre os membros do aglomerado, e que esperavam maior colaboração entre os membros a fim de se obter desenvolvimento do município.

Tal aspecto pode ser observado, visto que a competição é significativa no município, no qual
$73,3 \%$ dos sujeitos acreditam que as relações existentes entre as organizações presentes no município possuem interesses competitivos. No que se refere à ambiente de cooperação, dois atores expuseram que a rede apresenta exclusivamente esse ambiente, porém quando questionado sobre a presença de ambos os ambientes, 19 atores afirmaram a presença de tais. Ainda na análise univariada, 55,5\% dos entrevistados concordam que o aglomerado é benéfico para a cooperação entre os empresários locais.

Entretanto, o conceito de cooperação ainda é pouco utilizado. Isso é visualizado na afirmação de que "há oportunismo nas relações entre as empresas" no qual 36 atores concordaram com a mesma. Além disso, destaca-se a afirmativa de que "pode-se confiar na maioria dos empresários locais", em que $80 \%$ dos atores expuseram a falta confiança na maioria dos empresários municipais.

Assim, quando interrogados sobre quais seriam os principais motivos que os levariam a cooperar com as demais empresas, destaca-se que 24 empresários acreditam que o aumento de informações seria o principal motivo que os levariam a cooperar; 16 deles responderam que a redução dos custos também seria considerada nessa decisão; e 14 empresários indagaram que não existe cooperação entre os atores.

Porém, é importante ressaltar que a pergunta "quais seriam os motivos para cooperar" pode ter dado uma visão que tal item levaria um empresário a cooperar, mas isso não é algo que o mesmo faça de fato.

Como as empresas do aglomerado de Carmo do Cajuru possuem percepções diferentes sobre as formas de competição e cooperação, tornou-se necessário verificar em que consistem tais diferenças, e se elas possuem relação com outras características das empresas. Para isso foi realizado análise multivariada, especificadamente a análise de cluster.

Essa análise indicou a formação de dois cluster, aqui denominados de Cluster A e Cluster B, conforme indica a Tabela 1. 
Aglomerado produtivo competitivo ou cooperativo? $\mathrm{O}$ caso do aglomerado moveleiro do carmo do cajuru (MG)

Tabela 1. Perfil dos cluster A e B

\begin{tabular}{|c|c|c|}
\hline & Cluster A & Cluster B \\
\hline Número de atores & 26 atores & 17 atores \\
\hline Empresas participantes & $\begin{array}{l}1,3,4,8,10,12,13,14,18,19 \\
21,25,26,27,28,30,31,32,33,35 \\
36,37,38,39,40,41 .\end{array}$ & $\begin{array}{l}2,5,6,7,9,11,15,16,17,20, \\
22,23,24,29,34,42 \text { e } 43 .\end{array}$ \\
\hline Nascimento das empresas & $\begin{array}{l}\text { Predomina entre os anos de } 2001 \\
\text { a } 2010 \text {. }\end{array}$ & $\begin{array}{l}\text { Predomina entre os anos de } \\
1991 \text { a } 2000 \text {. }\end{array}$ \\
\hline Número de funcionários & Com até 10 funcionários. & De 11 a 20 funcionários. \\
\hline $\begin{array}{l}\text { Principais barreias } \\
\text { enfrentadas pelas empresas }\end{array}$ & Tarifas e impostos elevados. & $\begin{array}{l}\text { Concorrência acirrada e falta de } \\
\text { incentivos governamentais. }\end{array}$ \\
\hline Porte das Empresas & Micro e pequenas empresas. & $\begin{array}{l}\text { Predominam empresas } \\
\text { maiores. }\end{array}$ \\
\hline Interação com outros atores & $\begin{array}{l}\text { Proximidade geográfica }(28 \%) \text {; } \\
\text { laços familiares }(24 \%) \text {; feiras }(24 \%) \\
\text { e ocasiões sociais }(20 \%) \text {. }\end{array}$ & Outros meios $(17,6 \%)$ \\
\hline $\begin{array}{l}\text { Comprometimento } \\
\text { crescimento do setor }\end{array}$ & Falta de mão de obra. & Concorrência elevada. \\
\hline $\begin{array}{l}\text { Investimentos da Prefeitura } \\
\text { municipal }\end{array}$ & $\begin{array}{l}\text { Entrada de empresas de outros } \\
\text { setores no município; e investir nas } \\
\text { empresas moveleiras. }\end{array}$ & $\begin{array}{l}\text { Investimento voltados apenas } \\
\text { para as fábricas de móveis. }\end{array}$ \\
\hline
\end{tabular}

Fonte: elaborado pelos autores.

Embora o perfil dos dois clusters sejam bem diferentes, outros pontos precisam ser ressaltados. Embora o diferencial competitivo de ambos os grupos apresente pontos convergentes (o preço não é o principal diferencial competitivo, por exemplo), o Cluster A se revela indiferente quanto a característica de rapidez na entrega dos produtos, enquanto o Cluster B considera-o de extrema importância $(76,5 \%)$.

Ademais, o Cluster B considera como crucial o atendimento ao cliente como grande diferencial competitivo $(64,7 \%)$. Neste ponto se enfatiza que as diferentes percepções dos clusters em relação ao mercado se dá devido as próprias empresas presentes em nos clusters, sobretudo, no que refere aos seus portes. Nota-se, também, que o Cluster B é mais dependente de políticas públicas, uma vez que a maioria das empresas $(82,4 \%)$ acredita na importância do auxílio governamental para aumentar o nível de competitividade das empresas.

Além disso, grande parte dos atores desse grupo considera importante maior cooperação entre as empresas do setor $(64,7 \%)$ e a criação de cooperativa de compra e crédito $(68,8 \%)$, o que indica maior tendência à cooperação por parte desse grupo. Deferentemente, o Cluster A acredita que os fatores como investimento em infraestrutura $(62,2 \%)$ e maior divulgação da região produtora $(62,5 \%)$ seriam mais importantes para a competitividade. Nesse grupo, apenas $37 \%$ das empresas acreditam que a formalização das empresas informais seria benéfica para o aumento do nível de competitividade.

Com o intuito de verificar a validade da análise de cluster, bem como observar quais variáveis foram as mais relevantes para diferenciar os dois cluster formados, foi desenvolvido uma análise discriminante. Como hipótese nula, estabeleceu-se que não haveria diferenças entre os cluster.

O resultado da análise discriminante apontou a rejeição da hipótese nula, com nível de significância de $1 \%$ pelo teste de Lambda de Wilks. Desse modo, segundo o método stepwise, obteve-se as variáveis discriminadas: (I) 39 - A cooperação entre as empresas é incentivado pelos órgãos competentes no município; (II) 37 - O papel do sindicato é relevante para a união entre as organizações do município; (III) 52 - Acredito que a cooperação entre as empresas existe, apesar da competição grande entre elas; (IV) 42 - Pode-se verificar a ocorrência de oportunismo das relações entre as empresas; (V) 37 - Existe algum tipo de ação coletiva, tais como cooperativas ou grupos de comercialização, que dão sustentação ao setor; e (VI) 51 - As empresas de Carmo do Cajuru estão no mesmo nível de competitividade que as empresas de Ubá. 
A função discriminante apresentou um coeficiente de correlação canônica para a primeira função discriminante de 0,899 o que indica um alto grau de associação entre a função com os clusters analisados. Por último, as análises demonstraram que
97,7\% dos casos foram classificados corretamente, de acordo com a função discriminante. Para se obter maior entendimento do comportamento das variáveis discriminadas com os cluster, estabeleceu-se a Figura 3.

\begin{tabular}{|c|c|c|}
\hline Variáveis & Cluster A & Cluster B \\
\hline 39 & A maioria discorda da afirmativa. & A maioria discorda totalmente da afirmativa. \\
\hline 37 & $\begin{array}{l}\text { Visão mais restrita do papel do sindicato. } \\
\text { Opinião unificada sobre essa afirmativa }\end{array}$ & $\begin{array}{l}\text { Sindicato possui papel fundamental, do qual } \\
\text { a maioria concorda ou concorda plenamente } \\
\text { com essa afirmativa. }\end{array}$ \\
\hline 52 & $\begin{array}{l}\text { Acreditam que até ocorre cooperação } \\
\text { entre as organizações. }\end{array}$ & $\begin{array}{l}\text { Confusos sobre a alternativa. Metade } \\
\text { acredita que há cooperação apesar de grande } \\
\text { competição, porém a outra metade discorda ou } \\
\text { discorda totalmente. }\end{array}$ \\
\hline 42 & $\begin{array}{l}\text { Alto índice de oportunismo nos } \\
\text { relacionamentos existente. }\end{array}$ & $\begin{array}{l}\text { Todos os atores concordam ou concordam } \\
\text { totalmente haver presença de oportunismo. }\end{array}$ \\
\hline 37 & $\begin{array}{l}\text { Se sentem isolados no aglomerado. } \\
\text { Faltam grupos de apoio ou órgão que dê } \\
\text { sustentação ao setor. No entanto acreditam } \\
\text { que existem algum apoio por serem de } \\
\text { pequeno porte. }\end{array}$ & $\begin{array}{l}\text { Se sentem isolados no aglomerado. Faltam } \\
\text { grupos de apoio ou órgão que dê sustentação ao } \\
\text { setor. }\end{array}$ \\
\hline 51 & $\begin{array}{l}\text { Os integrantes discordam que as empresa } \\
\text { locais estão no mesmo nível de Ubá. }\end{array}$ & $\begin{array}{l}\text { Os integrantes discordam totalmente que as } \\
\text { empresas locais estão no mesmo nível de Ubá. } \\
\text { Necessidade de melhorar. }\end{array}$ \\
\hline
\end{tabular}

Figura 3. Comportamento das variáveis discriminadas nos Cluster A e B.

Portanto, pode-se inferir que a primeira categoria (Cluster A), bem como a segunda (Cluster B), tem como característica convergente que ambas são influenciadas pelo seu porte. Porém, como pontos divergentes, o Cluster A, tem em sua maioria micro e pequenas empresas, e o Cluster B, obtém maiores empresas. Além disso, os empresários da primeira categoria são mais otimistas em relação ao aspecto da cooperação entre organizações, mas percebem que comportamentos oportunistas, bem como a competição prevalecem. Já os empresários da segunda categoria são mais céticos a respeito as práticas de cooperação, no qual percebe-se uma certa polarização da ocorrência ou não desse aspecto.

Ainda sobre a comparação entre os dois clusters, cabe destacar a última variável discriminada "As empresas de Carmo do Cajuru estão no mesmo nível de competitividade que as empresas de Ubá". Assim, ambos os grupos concordam que o aglomerado de Carmo do Cajuru não pode ser comparado em questões de mercadológicas como o aglomerado de Ubá.

Segundo Bueno e Souki (2017) o aglomerado de Ubá se destina a produção de artigos mobiliários, incluindo produtos de madeira e metal. Assim o polo moveleiro se concentra em mais de 300 empresas, tornando-se um dos maiores polos moveleiros de Minas Gerais; tem atuação de mais de 30 anos; se compõe majoritariamente por pequenas e médias empresas, embora apresente empresas de grande porte; e a presença de associações e instituições de apoio são poucas e não muito participativas (Bueno $\&$ Souki, 2017).

No entanto, o arranjo atualmente representa expressiva participação no mercado e alto volume de vendas (Bueno \& Souki, 2017), e segundo o Diagnóstico do Polo Moveleiro de Ubá e Região (IEL, 2002), representa alto potencial de empregabilidade e destaca-se em primeiro lugar no número de estabelecimentos com o CNAE voltado para fabricação de móveis em Minas Gerais (IEL, 2002).

Por último, segundo o mesmo diagnóstico essa mesma indústria pode ser considerado como um arranjo produtivo local, uma vez que, além de concentrar grande quantidade de empresas com características similares, tem a economia de Ubá e região relacionada diretamente com os ciclos de desenvolvimento pautados no desempenho da indústria moveleira local (IEL, 2002).

Após a análise quantitativa, apresenta-se os argumentos das duas empresas entrevistadas. As 
Aglomerado produtivo competitivo ou cooperativo? $\mathrm{O}$ caso do aglomerado moveleiro do carmo do cajuru (MG)

empresas foram escolhidas com base nos cluster obtidos na parte de análise multivariada. Assim, denominou-se CA como empresário/empresa do Cluster A e CB como empresário/empresa do Cluster B. Ademais, as entrevistas foram separadas em dois blocos: interação e cooperação e competição.

Desse modo, iniciou-se as entrevistas abordando processos de interação e cooperação no aglomerado (primeiro bloco). Portanto, os empresários CA e CB foram interrogados sobre as interações entre as empresas. Assim, obteve-se as seguintes colocações:

[...] Algumas empresas sindicalizadas fazem parte de um APL, com o apoio do SEBRAE e FIEMG (CA).

[...] Não vejo quase nenhuma campanha entre os membros do aglomerado, apenas eventualmente é possível verificar algum contato (CB).

Além disso, quando questionados sobre as medidas para aumentar a interação, os entrevistados responderam:

[...] Poderia promover uma campanha para aumentar a filiação das empresas ao sindicato, tendo em vista que apenas $25 \%$ das empresas no município fazem parte do sindicato (CA).

[...] Penso que a melhor medida a ser adotada seria uma maior participação do setor público, com esse fazendo mais esforços no instituto de unir as organizações (CB).

Essas afirmações tornam mais evidente os motivos do arranjo ser classificada como aglomerado informal. Atrelado a isso, em contato informal com ex-proprietário de fábrica de móveis do município foi possível constatar que a grande maioria dos empresários locais desempenham papeis tanto dos gestores como de empregados do negócio, realizando todos os serviços, por falta de mão de obra especializada. Tal fato sobrecarrega esses agentes, de modo que dificulta a participação dos mesmo em reuniões dos sindicatos, em palestras esporádicas que ocorrem no aglomerado, dentro outras coisas. Assim, as aproximações ocorrem quando há uma grande necessidade, como, por exemplo, na compra conjunta de matéria-prima, tornando os laços entre os atores fraco.

A baixa interação presente no município extingue o estilo sistêmico visto em uma aglomeração, pois, embora as empresas estejam inseridas nesse tipo de ambiente, as redes de relacionamento são extremamente precárias.

O próximo passo analisado está relacionado com a cooperação presente no aglomerado. Conforme a teoria, um aglomerado tende a ser um local onde reina a cooperação entre os membros. Assim, esse tópico será analisado considerando seis categorias: percepção quanto ao ambiente de cooperação; propensão à cooperação; dificuldades para cooperar; benefícios da cooperação; e meio de cooperação atual da empresa.

$\mathrm{Na}$ primeira categoria, os entrevistados foram questionados sobre a suas percepções quanto ao ambiente de cooperação. Obteve-se, portanto, as seguintes afirmativas:

[...] Isso que ocorre atualmente é consequência de várias políticas passadas. Hoje em dia os moveleiros devem enxergar que a máquina pública é muito importante para o desenvolvimento do setor. (CA)

[...] Em minha opinião, só haverá aumento da cooperação no município se o setor público interferir (CB).

Conforme exposto nos trechos, as opiniões dos empresários são semelhantes. Segundo CA e CB, a cooperação precisa de um intermediário, ou seja, alguém para dar 'o pontapé inicial' e, caberia a prefeitura a intermediação capaz de aproximar as empresas do aglomerado. Ademais, os resultados apontaram também que se percebe que os dois empresários pouco buscam soluções para cooperar ao invés de competir, o que acarreta na procura de culpados pela falta de maiores cooperações.

Quando questionados sobre a situação do aglomerado cajuruense, segunda categoria, os empresários afirmaram:

[...] as empresas, apesar de concorrentes, podem se tornar aliadas em compras e até mesmo em vendas. Porém, precisam deixar de lado algumas diferenças. (CA)

[...] o mercado está aquecido e a cooperação iria alavancar ainda mais o setor. Entretanto, ressalto que seria necessária uma maior participação do setor público. (CB).

As duas organizações entrevistadas acreditam que a situação atual ainda é propícia à cooperação. Porém, deve-se atentar para o fato que ambas as empresas colocam ressalvas. Mais uma vez é notória a responsabilidade colocada sobre a prefeitura municipal.

A terceira categoria, questiona as dificuldades encontradas pelas organizações para cooperar com as demais. Os trechos seguintes foram extraídos:

[...] A diferença de situações financeiras compromete a confiabilidade. Empresas mais capitalizadas não veem vantagens em cooperar com 
empresas de menor porte e com pouco capital disponível. (CA)

[...] A principal dificuldade é a concorrência desleal que ocorre no município. Isso estremece a maioria dos relacionamentos. (CB)

Desses trechos, dois pontos precisam ser explorados. Para o entrevistado CA, a diferença de capital existente entre as empresas compromete a aliança entre as mesmas. Para o ator, somente a pequena empresa se beneficiaria da relação. Apontase, portanto, o ceticismo do entrevistado quanto a relação cooperativa entre empresas de maior porte com a dele, além do mesmo não ver benefícios em fazer parcerias com outras empresas que sejam de menor porte. Outro ponto a ser explorado é a questão da concorrência desleal proposto pelo entrevistado CB.

Em conversa com o entrevistado, o mesmo indica que a principal barreira ao aumento da cooperação no município poderia estar atrelada as reclamações dos atores sobre a grande cópia de produtos e à disputa por clientes.

A quarta categoria expressa os benefícios que o arranjo teria caso houvesse maior cooperação entre os atores. Dessa forma, os entrevistados argumentaram:

[...] Melhorando a infraestrutura nós poderíamos atender melhor nossos clientes, criar uma imagem melhor do município e consequentemente ter bons avanços no setor moveleiro. (CA)

[...] A cooperação poderia trazer, entre outras coisas, redução dos custos, aumento do poder de barganha junto a fornecedores e maior competitividade para as empresas inseridas no aglomerado. (CB)

Nos trechos selecionados ambos os entrevistados concordam que a cooperação traz benefícios, porém suas visões são diferentes. Segundo o entrevistado CA, a cooperação seria bem proveitosa se ela aumentasse a infraestrutura dos distritos industriais do município, o que impactaria no fortalecimento da marca. Já para o entrevistado $\mathrm{CB}$, a cooperação seria essencial para diminuir custos, aumentar o poder de comprar e, consequentemente, aumentaria a competição no aglomerado.

Na última categoria de análise, procurou-se saber quais são as práticas cooperativas das empresas. Assim, os trechos a seguir apontam-nas:

[...] Indicação de fornecedores. Compartilhamento de clientes, busca de novas tecnologias em feiras. (CA)
[...] Apenas a troca de experiencias com algumas empresas (chão de fábrica). (CB)

Para a empresa CA, apesar de ressaltar durante a maior parte da entrevista que é baixa a cooperação no aglomerado, tem interações consideráveis com as demais empresas, como compra de matéria-prima, indicação de clientes e busca de tecnologia, esta última ressaltada por meio de uma viagem feita a Itália na busca de novas tendências.

Apesar de ser um pequeno passo, a viagem demonstra ações pontuais, porém conjuntas na região. Já a empresa $\mathrm{CB}$ indicou que a cooperação ocorrida seria apenas no chão de fábrica, não havendo outros meios de interação com os 'concorrentes'.

A outra parte da entrevista abordou os processos de competição no aglomerado produtivo (segundo bloco). Desse modo, três categorias foram analisadas: competição versus cooperação; desvantagens da competição; e benefícios da competição.

A primeira categoria de análise é a competição versus cooperação. Dois trechos foram extraídos da entrevista.

[...] Como as empresas possuem os clientes como seu bem de maior valia, acaba comprometendo qualquer tipo de cooperação, pois há o medo dos concorrentes "roubarem" seus clientes. (CA)

[...] No aglomerado ao qual estamos inseridos, por mais que aja algum vestígio de cooperação, a competição supera. Mesmo que uma empresa coopere com a outra, ela está competindo ao mesmo tempo. (CB)

Como visto anteriormente nas entrevistas a competição aparentemente supera a cooperação no município. Segundo os entrevistados as duas formas coexistem dentro da aglomeração.

A segunda categoria abordada foram as desvantagens da competição, ou seja, quais são as perdas ocorridas por decorrência da competição. Os trechos abaixo apresentam as afirmativas dos entrevistados:

[...] A cópia de produtos por parte dos concorrentes é um dos grandes obstáculos que enfrento ultimamente. Muitos produtos que antes eram exclusivos, hoje são fabricados por outras organizações e com isso perco espaço no mercado. (CA)

[...] Com a grande competição no município não há como expor nossos casos de sucesso, pois caso 
Aglomerado produtivo competitivo ou cooperativo? $\mathrm{O}$ caso do aglomerado moveleiro do carmo do cajuru (MG)

isso aconteça haverá cópias dos meus produtos e, consequentemente, perderei mercado. (CB)

O consenso entre os entrevistados é sobre a cópia dos produtos. Porém como o setor moveleiro em análise é segmentado, essa competição ocorre em determinadas áreas e não no aglomerado em geral.

Ou seja, a competição não se dá entre todos os empresários, mas entre os que fabricam um mesmo tipo de produto. Ademais, ao serem questionados sobre os motivos de nenhuma empresa possui um site, para demonstrar suas novidades e aproximar dos seus clientes, a resposta foi relacionada 'a cópia dos produtos seria ainda maior'.

Apesar das altas reclamações acerca da competição no aglomerado, as empresas veem competição como algo favorável, como pode ser verificado nos trechos selecionados da terceira análise:

[...] Apesar de muitas vezes a competição causar grandes prejuízos, penso que através dela que há incentivo para desenvolvimento de novos produtos, pela busca de melhores tecnologias e exploração de novos mercados. A competição não deixa a firma "acomodar". (CA)

[...] A competição tem como maior benefício a busca por todos de uma maior qualidade dos produtos e serviços prestados. (CB)

Segundo os entrevistados, a competição é benéfica pois "força” o desenvolvimento contínuo de todas as organizações, sobretudo no que se trata de novos produtos. $\mathrm{O}$ ambiente competitivo é altamente favorável ao desenvolvimento de novas tecnologias. No entanto, apesar dos entrevistados afirmarem que ela é benéfica, deixaram transparecer que atualmente ela é mais destrutiva que construtiva. No próximo tópico apresenta-se as principais discussões sobre os dados encontrados, bem como são apontadas as contribuições teóricas e gerenciais.

\section{DISCUSSÕES}

Embasados no tópico anterior foi possível estabelecer a Figura 4, a qual sintetiza os principais resultados.

\begin{tabular}{|c|c|}
\hline Análise de Dados & Principais Resultados \\
\hline Univariada & $\begin{array}{l}\text { - Pouca cooperação entre os membros; } \\
\text { - Esperam maior cooperação; } \\
\text { - Competição maior entre os membros } \\
\text { - Oportunismo na rede; } \\
\text { - Falta de confiança. }\end{array}$ \\
\hline Multivariada & $\begin{array}{l}\text { - Cluster A (micro e pequenas empresas); } \\
\text { - Cluster B (maiores empresas); } \\
\text { Variáveis discriminadas: } \\
\text { - A cooperação entre as empresas é incentivada pelos órgãos competentes no } \\
\text { município; } \\
\text { - O papel do sindicato é relevante para a união entre as organizações do município; } \\
\text { - A cooperação entre as empresas existe, apesar da competição grande entre elas; } \\
\text { - Pode-se verificar a ocorrência de oportunismo das relações entre as empresas; } \\
\text { - Existe algum tipo de ação coletiva, tais como cooperativas ou grupos de } \\
\text { comercialização, que dão sustentação ao setor; e } \\
\text { - As empresas de Carmo do Cajuru estão no mesmo nível de competitividade que } \\
\text { as empresas de Ubá. }\end{array}$ \\
\hline Conteúdo & $\begin{array}{l}\text { - Visão do aglomerado (poucas interações entre as empresas); } \\
\text { - Aumento das interações (afiliação ao sindicato e maior participação do setor } \\
\text { público) } \\
\text { Categoria Cooperação: } \\
\text { - Percepção quando ao ambiente de cooperação (necessidade de um intermediário } \\
\text { - órgãos públicos); } \\
\text { - Propensão à cooperação (necessidade do setor público); } \\
\text { - Dificuldades para cooperar (diferentes portes e concorrência desleal); } \\
\text { - Benefícios de cooperar (infraestrutura para atender clientes, imagem do } \\
\text { município, redução de custos, poder de barganha e competitividade); } \\
\text { - Meios de cooperação atual das empresas (indicação de fornecedores e } \\
\text { compartilhamento de clientes, novas tecnologias, troca de experiências); } \\
\text { Categoria Competitividade: } \\
\text { - Competitividade vs. Cooperação (competição supera a cooperação); }\end{array}$ \\
\hline
\end{tabular}




\section{- Desvantagens da competição (cópia de produtos);}

- Benefícios da competição (inovação em produtos).

Figura 4. Síntese dos resultados.

Dessa forma, alguns pontos ser ressaltados. Inicialmente, os resultados apresentam a percepção dos membros em relação ao aglomerado bem como aos seus benefícios. Assim sendo, os membros, percebem que a rede pode ser benéfica para as empresas, visto que podem proporcionar infraestrutura para atender clientes, melhorar a imagem do município, reduzir custos e aumentar o poder de barganha e competitividade das empresas. Porém, quanto aos objetivos estratégicos da rede, a opinião dos grupos se difere.

Tais resultados são convergentes com a literatura. Desse modo, somente pelos associados do aglomerado perceberem a necessidade de atuarem no formato de redes, permite inferir que os mesmos, na condição de empresas pequenas, buscam aumentar oportunidades de cooperarem com outros atores, elevando os potenciais de competitividade no mercado, por meio de melhores condições de desenvolvimento de suas atividades (Galbraith, Rodrigues \& DeNoble, 2008; Gomez \& Helsing, 2008).

Ainda no que se refere aos benefícios da atuação em redes, Cunha (2002), Verschoore e Balestrin (2008) e Balestrin e Verschoore (2016) apontam ganhos competitivos, que podem ser por geração de soluções coletivas, inovação colaborativa, acumulo de capital social, ampliação de mercado, aprendizagem coletiva, economia de escala e escopo, poder de mercado e redução de custos e riscos. Tais ganhos foram observados e apontados pelos sujeitos da pesquisa.

Outro ponto importante, que deve ser ressaltado, está relacionado com aos desajustes estratégicos. Em outras palavras, verificou-se que as percepções dos sujeitos, quanto aos investimentos a serem realizados no aglomerado, são diferentes. Para Wegner e Padula (2012) e Brouthers, Brouthers e Wilkinson (1995) a cooperação falha a medida que há desajustes na percepção do que é melhor para a rede e, consequentemente, para as empresas. Segundo os mesmos autores, é natural que haja desajustes entre as empresas, porém é no processo de cooperação que essas diferenças se tonem latentes e precisam, assim, ser gerenciadas pelos atores e líderes das redes.

Pode-se destacar, também, a atuação dos mesmos perante o arranjo. Desse modo, verificou-se pelas análises que os atores esperam maior cooperação dentro da rede, porém acreditam que os incentivos para esta devem vir de órgãos competentes como governo e sindicato. Tal percepção dos sujeitos está convergente com o argumento de Porter (1999), em que o governo deve incentivar a melhoria do cluster e motivar, facilitar e proporcionar incentivos à ação coletiva pelo setor privado.

Porém, cabe enfatizar dois pontos acerca desses resultados que necessitam ser criticados: (i) conforme vários pontos do trabalho, os atores atribuem grande parte da responsabilidade pela condução da rede aos órgãos governamentais, retirando as suas próprias responsabilidades da condução e do êxito do aglomerado; e (ii) se faz nítida a falta de liderança da rede. Segundo Tonin, Ravanello, Bertóli e Tonin (2016) e Lipman-Blumen (1999) por falta de hierarquia formal, as redes necessitam de líderes, que estimulem a cultura do compartilhamento, divisão do poder e de informações, proativa, flexível, motivadora e incentivadora, com o intuito de manter a coesão interna da rede, tendo como foco os valores e interesses comuns.

Sobre a cooperação, em todas as coletas e análise de dados verificou-se que há pouca cooperação no arranjo, sendo que ora os membros percebem poucas ações coletivas, ora se sentem isolados na rede. Isso converge com a argumentação dos mesmos de que há poucas interações entre as empresas e das mesmas com os órgãos públicos da região. Esse resultado foi ressaltado pelo IEDI (2003), de que no Brasil, alguns estudos sobre clusters constataram que na maioria dos casos não há formas relevantes de cooperação entre as empresas, e por Lemos (1997), de que os aglomerados podem ser caracterizados por estreita colaboração entre firmas e demais agentes.

Como dificuldades para a cooperação os atores apontaram a maior competição entre os membros, concorrência desleal, falta de confiança, diferentes percepções da rede, diferentes situações financeiras das empresas na rede (o que compromete a confiança nas mesmas) e oportunismo. Todos esses aspectos podem ser enquadrados em duas categorias apontadas por Park e Ungson (2001) e Wegner e Padula (2012): rivalidade entre as firmas e complexidade gerencial. Sendo que, essa última, está diretamente associada aos desajustes estratégicos. 
Aglomerado produtivo competitivo ou cooperativo? $\mathrm{O}$ caso do aglomerado moveleiro do carmo do cajuru (MG)

Assim, conforme os atores apontam, essas duas categorias levam a problemas com confiança, reputação e comprometimento das empresas à rede (o que está implícito nos resultados obtidos), o que gera, por consequência, a falta de equidade, eficiência e adaptação na rede. Logo há falta de alianças no aglomerado. Tal resultado é encontrado na rede, sobretudo pelos pontos mencionados por ambos os representantes dos grupos de que "há pouca interação das empresas na rede".

Ainda nesse sentido, tem-se que, pela percepção dos investigados, a competição sobressai as práticas cooperativas. Tal aspecto condiz com os apresentados por Porter (1999), Ferraz, Kupfer e Haguenauer (1995) e Possas (1999), de que em aglomerados encontra-se tanto competição quanto cooperação e que o padrão de competição influencia a cooperação. Assim, essas duas formas coexistem dentro da aglomeração.

Como desvantagem de maior competição dentro da rede obteve-se a rivalidade por meio da cópia de produtos, visto que embora as empresas vislumbrem a cooperação, não foi observado boa vontade dos participantes de compartilhar informações e técnicas com os "concorrentes locais", por causa da cópia de produtos. Já como vantagens, destaca-se a inovação de produtos, uma vez que segundo Leão (2005), a intensidade da competição entre os agentes ou empresas é um determinante crítico do desenvolvimento de novos produtos e tecnologias.

Conforme todos os dados apresentados, é possível, portanto, enquadrar o aglomerado produtivo do Carmo de Cajuru como um aglomerado informal, em que, segundo Iacono e Negano (2007), é constituído pela maioria de pequenas empresas (conforme resultado da análise de cluster), com baixa sofisticação baixa sofisticação tecnológica e capacidade gerencial. Apresentam também, mão de obra de baixa qualificação, infraestrutura inadequada, ausência de apoio financeiro e poucas inovações. Em relação à coordenação e à cooperação, nesse tipo de aglomerado as relações são fracas, com pouca confiança, muita competição e baixo compartilhamento de informação.

Os aglomerados informais são prevalecentes em países em desenvolvimento como o Brasil, e o papel do Estado, através de políticas públicas que visem o fornecimento de serviços tecnológicos, treinamento e crédito, tem mostrado ser de fundamental importância para o crescimento desses aglomerados.
Por último aspecto, ao se considerar as vantagens advindas da localização geográfica propostas por Marshall (1996), pode-se verificar que nenhuma dessas foi possível verificar no referido aglomerado. Em outras palavras, os dados refletiram que a localização conjunta das empresas não apresentou atração a fornecedores altamente especializados, mão de obra qualificada e difusão de informações, sendo essas pontos insatisfatórios dos próprias empresas moveleiras. Nesse sentido, também não foram observados, no referido aglomerado, as externalidades pecuniárias, conforme aponta Johansson (2005), sobretudo aqueles advindos da redução dos custos de transação e compras, vendas e distribuição conjuntas. No entanto, há presença de externalidades tecnológicas positivas e negativas, uma vez que a competição provoca o desenvolvimento de novos produtos, por meio de tendências de mercado e tecnologias (positivas), e as cópias intensificam os fluxos de conhecimentos (negativas).

Por fim, o próximo tópico apresenta as considerações finais, bem como as contribuições, limitações e agenda para pesquisas futuras.

\section{CONSIDERAÇÕES FINAIS}

O presente estudo teve como objetivo principal caracterizar o processo de cooperação no aglomerado moveleiro do Carmo do Cajuru (MG). Como resultado do primeiro objetivo especifico, identificar a rede de empresas e estrutura de apoio ao desenvolvimento do aglomerado, obteve-se que o arranjo pode ser dividido em dois grupos diferentes de empresas. Assim, o Grupo A se compõe de 26 empresas, sendo elas de micro e pequeno porte, com até de 10 empresas e iniciaram suas atividades entre os anos de 2001 a 2010. Já o segundo Grupo, B, se compõe de 17 atores, de porte médio e grande, com mais de 10 funcionários e iniciaram suas atividades entre 1991 a 2000. No que se refere a estrutura de apoio, os sujeitos apontam atividades pontuais dos órgãos públicos (sindicatos e governo municipal), bem como, na maioria das vezes, se sentem isolados.

Para o segundo objetivo especifico, caracterizar os processos de cooperação e competição do cluster, pode-se verificar que, embora as percepções dos atores do aglomerado cajuruense sobre a competição e cooperação sejam diferentes, ambos concordam que a competição sobressai sobre a cooperação. Ao que tange as diferenças de percepções, esta é associada aos diferentes perfis de empresas do aglomerado. Desse modo, no Cluster A, os atores são 
mais otimistas em relação ao aspecto da cooperação entre organizações, porém percebem comportamentos oportunistas, bem como a competição prevalece no aglomerado. Já as empresas do Cluster B são mais céticas a respeito as práticas de cooperação, no qual percebe-se uma certa polarização da ocorrência ou não desse aspecto. Ressalta-se que nessa categoria, as empresas também acreditam que o comportamento oportunista e competitividade são maiores do que as práticas cooperativas dos atores.

Nas entrevistas, observou-se que o aglomerado cajuruense ainda é informal e permanece propício a cooperação. No entanto, atribui-se essa responsabilidade a órgão intermediador, no caso o governo. Embora haja dificuldades para efetuar a cooperação, como diferença de capital e concorrência desleal, os entrevistados enxergam que as interações podem trazer benefícios. Já ao que se concerne a competição, foi possível verificar que a mesma influencia a forma como ocorre a cooperação, uma vez que os entrevistados alegaram que praticam a cooperação, porém de forma receosa, devido ao problema de cópia de produtos. Outro aspecto importante é a competição não traz somente aspectos desfavoráveis, mas também 'força' as empresas a se desenvolverem continuamente, sobretudo em seus portfólios de produtos. Entretanto, mesmo com esse benefício, a competição se mostra mais destrutiva que construtiva.

Como contribuições destaca-se as teóricas e gerenciais. No âmbito teórico, o estudo pode contribuir para a consolidação das teorias interorganizacionais, com enfoque nos aglomerados produtivos. Em outras palavras, os resultados aqui mencionados condizem com a literatura corrente, fortalecendo, assim, os estudos sobre redes de empresas. Ademais, ressalta-se que o estudo contribui para a visão dos arranjos no contexto brasileiro, visto que, devido às condições e contexto singulares do País, os aglomerados se dão e se desenvolvem, muitas das vezes, de forma diferente dos países estrangeiros. Verifica-se isso, sobretudo numa visão mais passiva das empresas em relação aos negócios do aglomerado e a geração de grande expectativa em relação aos órgãos governamentais e de apoio, o que contribui para a consolidação da literatura nacional sobre a temática.

No âmbito das práticas gerenciais, a pesquisa apresenta, em seu decorrer, várias indicações intrínsecas para a gestão de aglomerações produtivas. Destaca-se, portanto, a conscientização das empresas acerca das suas atribuições e responsabilidade, da cobrança dos órgãos governamentais e de políticas públicas para auxílio à rede, necessidade de lideranças mais atuantes e gerenciamento e ações pontuais para diminuição de rivalidade entre os membros e complexidade gerencial.

Como limitação do estudo, destaca-se que a pesquisa foi realizada considerando apenas a perspectiva dos empresários do aglomerado. Como sugestão de pesquisas futuras, aconselha-se a verificação das perspectivas das instituições presentes no aglomerado, como a Prefeitura Municipal, Senai, Sindicato e outros órgãos envolvidos. Ademais, a realização do mesmo tipo de pesquisa com o aglomerado de empresas de Ubá seria interessante, para efeitos de comparação.

\section{REFERÊNCIAS}

Balestrin, J. A \& Verschoore, J. (2016). Redes de cooperação empresarial: estratégias de gestão na nova economia ( $2^{\mathrm{a}}$ ed.). Porto Alegre: Brookman. Contabilidade, Gestão e Governança, 16(3), 3-16.

Balestro, M. V. (2004). Características estruturais e mecanismos de governança em redes de cooperação: apontamentos conceituais. In Verschoore, J. R. (Org.). Redes de cooperação: uma nova organização de pequenas e médias empresas no Rio Grande do Sul. Porto Alegre: FEE, 49-67.

Bardin, L. (2016). Análise de conteúdo. Lisboa: edições, 70, 225.

Best, M. H. (1990). The new competition: institutions of industrial restructuring. Harvard University Press.

Brito, J. (2004) Cooperação e aprendizado em arranjos produtivos locais: em busca de um referencial analítico. In Lastres, H. M. M. \& Cassiolato J. E. (Org.). Arranjos produtivos locais: uma nova estratégia de ação para o Sebrae: relatório de atividades do referencial conceitual, metodológico, analítico e propositivo.

Rede de Pesquisa em Sistemas Produtivos e Inovativos Locais. [S. 1.: s. n.], 23 p.

Brouthers, K. D., Brouthers, L. E., \& Wilkinson, T. J. (1995). Strategic alliances: Choose your partners. Long range planning, 28(3), 2-25.

Bueno, E. M., \& Souki, G. Q. (2017). Análise da cadeia produtiva moveleira da microrregião de UBÁ/MG sob a perspectiva de cluster. Revista 
Aglomerado produtivo competitivo ou cooperativo? $\mathrm{O}$ caso do aglomerado moveleiro do carmo do cajuru (MG)

Observatorio de la Economía Latinoamericana, Brasil, (enero 2017).

Casarotto Filho, N., \& Pires, L. H. (2001). Redes de Pequenas e Médias empresas e desenvolvimento local: estratégias para a competitividade global com base na experiência italiana. ( $2^{\circ}$ Ed.). São Paulo: Atlas.

Castells, M., \& Cardoso, G. (Eds.). (2006). The network society: From knowledge to policy (pp. 323). Washington, DC: Johns Hopkins Center for Transatlantic Relations.

Creswell, J. W., \& Clark, V. L. P. (2017). Designing and conducting mixed methods research. Sage publications.

Crocco, M. A., Galinari, R., Santos, F., Lemos, M. B., \& Simões, R. (2006). Metodologia de identificação de aglomerações produtivas locais. Nova economia, 16(2), 211-241.

Cunha, I. J. (2002). Aglomerados industriais de economias em desenvolvimento: classificação e caracterização. Edeme.

Diomar (2000). História de Carmo do Cajuru: 1747-2000. Carmo do Cajuru: Off Set.

Enright, M. J. (2003). Regional clusters: what we know and what we should know. In: Bröcker, J.; Dohse, D. \& Soltwedel, R. (Org.). Innovation clusters and interregional competition. Kiel: Springer. p. 99-129.

Erber, F. S. (2008). Eficiência coletiva em arranjos produtivos locais industriais: comentando o conceito. Nova economia, 18(1), 11-31.

Evans, M. (2003). Evolution of Cooperation. In West, M. A., Tjosvold, d. \& Smith, K. G. (Eds.). International handbook of organizational teamwork and cooperative working (pp. 45-54). New York, NY: Wiley.

Fan, C. C., \& Scott, A. J. (2003). Industrial agglomeration and development: a survey of spatial economic issues in East Asia and a statistical analysis of Chinese regions. Economic geography, 79(3), 295-319.

Ferraz, J. C., Kupfer, D., \& Haguenauer, L. (1995). Made in Brazil: desafios competitivos para a indústria. Rio de janeiro: Campus, 386.
Forza, C. (2002). Survey research in operations management: a process-based perspective. International journal of operations \& production management, 22(2), 152-194.

Galbraith, C. S., Rodriguez, C. L., \& DeNoble, A. F. (2008). SME competitive strategy and location behavior: An exploratory study of high-technology manufacturing. Journal of Small Business Management, 46(2), 183-202.

Gil, A. C. (2010). Métodos e técnicas de pesquisa social. ( $6^{\circ}$ Ed.) Atlas, São Paulo, 200p.

Godoy, A. S. (2005). Refletindo sobre critérios de qualidade da pesquisa qualitativa. GESTÃO.Org Revista Eletrônica de Gestão Organizacional, 3(2).

Gomez, G. M., \& Helmsing, A. H. J. (2008). Selective spatial closure and local economic development: What do we learn from the Argentine local currency systems?. World Development, 36(11), 2489-2511.

Hair Junior, F., Black, W. C., Babin, B. J., Anderson, R. E., \& Tatham, R. L. (2009). Análise multivariada de dados. Bookman Editora.

Iacono, A., \& Nagano, M. S. (2007). Uma análise e reflexão sobre os principais instrumentos para o desenvolvimento sustentável dos arranjos produtivos locais no Brasil. Revista Gestão Industrial, 3(1).

Instituto de Estudos para o Desenvolvimento Industrial (IEDI). (2003). Os sistemas locais de produção/Inovação - Caras novas na discussão das políticas industrial e tecnológica. São Paulo. Carta n. 54.

Instituto Euvaldo Lodi (IEL). (2002). Diagnóstico do Polo Moveleiro de Ubá e Região. Belo Horizonte: IEL-MG, 65p.: graf. FIEMG.

Johansson, B. (2005). Parsing the menagerie of agglomeration and network externalities. In: Karlssson, C., \& Stough, R. R. Industrial cluster and inter-firm networks. Cheltenham: E. E. Publishing, p. 107-147.

Johnson-Cramer, M. E.; Parise, S \& Cross, R.L. (2007) Managing chande throught networks and values. California Management Review, 47(3), 85109. 
Lastres, H. M., \& Cassiolato, J. E. (2003). Glossário de arranjos e sistemas produtivos $e$ inovativos locais. Rio de Janeiro: IE.

Leão, D. A. F. S. (2005). Relevância da teoria da coopetição para a compreensão da dinâmica dos relacionamentos entre empresas concorrentes. In $I I$ Encontro de Estudos em Estratégia. Anais ... Rio de Janeiro: ANPAD.

Lemos, C. (1997). Notas preliminares do projeto arranjos locais e capacidade inovativa em contexto crescentemente globalizado. IE/UFRJ, Rio de Janeiro, mimeo.

Lincoln, Y. S., \& Guba, E. G. (1986). But is it rigorous? Trustworthiness and authenticity in naturalistic evaluation. New directions for program evaluation, 1986(30), 73-84.

Linhares, L. (2008). Arranjos Produtivos Em Espaços Periféricos: Análise Multivariada Para Minas Gerais. In XIII Seminário sobre a Economia Mineira [Proceedings of the 13th Seminar on the Economy of Minas Gerais]. Anais... Cedeplar, Universidade Federal de Minas Gerais.

Lipman-Blumen, J. (1999). Liderança conectiva: como liderar em um novo mundo de interdependências, diversidade e virtualmente conectado. São Paulo: Makron Books.

Lübeck, R. M., Wittmann, M. L., \& Silva, M. S. (2012). Afinal, Quais Variáveis Caracterizam a Existência de Cluster Arranjos Produtivos Locais (APLs) e dos Sistemas Locais de Produção e Inovação (SLPIs)?. Revista Ibero Americana de Estratégia, 11(1).

Machado, S. A. (2003). Dinâmica dos arranjos produtivos locais: um estudo de caso em Santa Gertrudes, a nova capital da cerâmica brasileira. Tese de Doutorado em Engenharia de Produção. Escola Politécnica, Universidade de São Paulo, São Paulo.

Malhotra, N. K. (2011). Pesquisa de marketing: foco na decisão. ( $3^{\circ}$ Ed.). São Paulo: Pearson Prentice Hall.

Malhotra, M. K., \& Grover, V. (1998). An assessment of survey research in POM: from constructs to theory. Journal of operations management, 16(4), 407-425.
Marconi, M. A., \& Lakatos, E. M. (2005). Fundamentos de Metodologia Científica. ( $6^{\circ}$ Ed.). São Paulo: Atlas, 2005.

Maroco, J. (2010). Análise estatística: com utilização do SPSS. Lisboa, Edições Silabo.

Marshall, A. (1966). Principles of Economics: An introductory volume. ( $8^{\circ} \mathrm{Ed}$.). London: Macmillan.

Matheus, M. R. F. B. (2003). Cluster e desenvolvimento local: um estudo exploratório das empresas moveleiras de Carmo do Cajuru. In: $X V$ Prêmio Minas de Economia, Anais... Belo Horizonte.

Mendonça, F. M. de. (2010). Formação, desenvolvimento e estruturação de arranjos produtivos locais da indústria tradicional do Estado de Minas Gerais. São Paulo: Blucher.

Mendonça, F. M. (2008). Formação, desenvolvimento e estruturação de arranjos Produtivos locais da indústria tradicional do estado de Minas Gerais. Tese de Doutorado em Engenharia de Produção. Universidade Federal do Rio de Janeiro, Rio de Janeiro.

Morse, J. M. (1991). Approaches to qualitativequantitative methodological triangulation. Nursing research, 40(2), 120-123.

Nohria, N. (1992). Is a network perspective a usefull way of studyng organizations?. In Nohria, $\mathrm{N}$ \& Eccles, R. G. Networks and organizations: structure, form and action (1-22). Boston: Harvard Business School Press.

Oliveira, M. F., \& Gonçalves, C. A. (2011). Estratégia cooperativa em redes organizacionais: um estudo em polo turístico de Minas Gerais. Revista Ibero Americana de Estratégia, 10(2).

Park, S. H., \& Ungson, G. R. (2001). Interfirm rivalry and managerial complexity: A conceptual framework of alliance failure. Organization science, $12(1), 37-53$

Pedrosa, P. T. M., Antunes, L. G. R., Morais, R. \& Rodrigues, T. C. (2018). Vale da Eletrônica e Poder Público Municipal: Desvelando suas Relações acerca do APL de Santa Rita do Sapucaí (MG). In $X$ Encontro de Estudos sobre Empreendedorismo e Gestão de Pequenas Empresas, Anais... São Paulo (SP). 
Aglomerado produtivo competitivo ou cooperativo? $\mathrm{O}$ caso do aglomerado moveleiro do carmo do cajuru (MG)

Porter, M. E. (1999). Competição: estratégias competitivas essenciais. Rio de Janeiro: Campus.

Porter, M. E. (1998). Clusters and the new economics of competition. Harvard Business Review, Boston, p.77-90.

Possas, M. S. (1993). Concorrência e competitividade: notas sobre estratégia e dinâmica seletiva na economia capitalista. São Paulo: Hucitec.

Puga, F. (2003). Alternativas de apoio a MPMES localizadas em arranjos produtivos locais.[SL]: BNDES.

Pugas, P. G. O., \& Fernandes, R. D. S. (2014). Externalidades positivas em aglomerações de empresas: um estudo no aglomerado de fundição da cidade de Cláudio (MG), Brasil. Gestão \& Regionalidade, 30(89), 49-62.

Rangone, A. (1999). A resource-based approach to strategy analysis in small-medium sized enterprises. Small business economics, 12(3), 233248.

Relatório Anual de Informações Sociais (RAIS). (2009). Recuperado de <http://sgt.caged.gov.br/index.asp>.

Ring, P. S. (1999). The costs of networked organization. In: Grandori, A. Interfirm networks: organization and industrial competitiveness. London: Routledge.

Roxo, L. A. T., Santarossa, E. T., \& Bertotti, G. (2011). Aglomerados produtivos e concentração: uma análise terórico-conceitual. In: $V$ Encontro de Economia Catarinense, Anais..., Florianópolis (SC).

Saublens, C. (1999). Clusters, Industrial Districts, Local Produtive Systems. Eurorapport, $\mathrm{n}^{\circ} 6$, Bruxelas, Eurada.

Selltiz, C. (1965). Métodos de pesquisa nas relações sociais. São Paulo: Herder.
Snow, C. C. (2015). Organizing in the age of competition, cooperation, and collaboration. Journal of leadership \& organizational studies, 22(4), 433442.

Thomazi, S. M. (2006). Cluster de turismo: introdução ao estudo de arranjo produtivo local. Aleph.

Tonin, G. A., da Silva Ravanello, F., Bertóli, N. C., \& Tonin, S. (2016). A Formação de Redes de Empresas: o caso da região central do Rio Grande do Sul-RS. Future Studies Research Journal: Trends and Strategies, 8(3), 3-30.

Vale, G. M. V. (2007). Territórios Vitoriosos: o papel das redes organizacionais. Rio de Janeiro: Garamond.

Vergara, S. C. (2015). Métodos de Pesquisa Qualitativa em Administração. (6 ${ }^{\circ}$. Ed). Atlas, São Paulo.

Verschoore, J. R., \& Balestrin, A. (2008). Fatores relevantes para o estabelecimento de redes de cooperação entre empresas do Rio Grande do Sul. RAC-Revista de Administração Contemporânea, 12(4).

Yin, R. K. (2005). Estudo de Caso: Planejamento e Métodos. (3a. Ed.). Porto alegre: Bookman.

Wegner, D., \& Padula, A. D. (2012). Quando a cooperação falha: um estudo de caso sobre o fracasso de uma rede interorganizacional. Revista de Administração Mackenzie (Mackenzie Management Review), 13(1).

Williamson, O. E. (2003). Examining economic organization through the lens of contract. Industrial and Corporate Change, United Kingdom, v. 12, p. $917-942$. 